\title{
Effect of photodynamic therapy on the extracellular matrix and associated components
}

M.d.C. Pazos and H.B. Nader
Departamento de Bioquímica, Escola Paulista de Medicina, Universidade Federal de São Paulo, São Paulo, SP, Brasil

\begin{abstract}
Correspondence
M.d.C. Pazos

Departamento de Bioquímica UNIFESP/EPM

Rua Três de Maio, 100, 4ํandar 04044-020 São Paulo, SP

Brasil

Fax: +55-11-5573-6407

E-mail: marcelo.pazos@gmail.com

In honor of Prof. Carl P. Dietrich.

Research supported by CNPq, CAPES and FAPESP.
\end{abstract}

Received February 2, 2007

Accepted May 11, 2007

\begin{abstract}
In many countries, photodynamic therapy (PDT) has been recognized as a standard treatment for malignant conditions (for example, esophageal and lung cancers) and non-malignant ones such as age-related macular degeneration and actinic keratoses. The administration of a non-toxic photosensitizer, its selective retention in highly proliferating cells and the later activation of this molecule by light to form reactive oxygen species that cause cell death is the principle of PDT. Three important mechanisms are responsible for the PDT effectiveness: a) direct tumor cell kill; b) damage of the tumor vasculature; c) post-treatment immunological response associated with the leukocyte stimulation and release of many inflammatory mediators like cytokines, growth factors, components of the complement system, acute phase proteins, and other immunoregulators. Due to the potential applications of this therapy, many studies have been reported regarding the effect of the treatment on cell survival/death, cell proliferation, matrix assembly, proteases and inhibitors, among others. Studies have demonstrated that PDT alters the extracellular matrix profoundly. For example, PDT induces collagen matrix changes, including cross-linking. The extracellular matrix is vital for tissue organization in multicellular organisms. In cooperation with growth factors and cytokines, it provides cells with key signals in a variety of physiological and pathological processes, for example, adhesion/migration and cell proliferation/differentiation/death. Thus, the focus of the present paper is related to the effects of PDT observed on the extracellular matrix and on the molecules associated with it, such as, adhesion molecules, matrix metalloproteinases, growth factors, and immunological mediators.
\end{abstract}

\section{Introduction}

Photodynamic therapy (PDT) is a standard treatment for various cancers (lung, esophagus, stomach, cervix, bladder, etc.) as well as for non-malignant conditions such as age-related macular degeneration, actinic keratoses and psoriasis. It is based on the
Key words

- Photodynamic therapy

- Extracellular matrix

- Adhesion

- Chemical mediators

- Matrix metalloproteinases

................... 
species ultimately eliminate highly proliferating cells by damaging membranes, DNA and other cell structures, and also by affecting extracellular matrix (ECM) components.

ECM is a complex network of macromolecules secreted by the cells. It resides between cells as both a barrier and a scaffold on which tissues are built. It is composed of carbohydrates and proteins including adhesion proteins such as fibronectin, vitronectin, laminin, tenascin, and collagen. Cell adhesion and the ECM are involved in signal transduction during a variety of cell functions such as cell motility, morphogenesis, differentiation, and proliferation. In addition to ECM-intracellular signal transduction, cell-cell communication takes place in the extracellular environment when a chemical secreted by a signaling cell interacts with a receptor on the membrane of a second (signal receiving) cell (2). Thus, cell migration comprises cell-cell adhesion and cell-

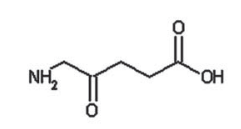

Aminolevulinic acid

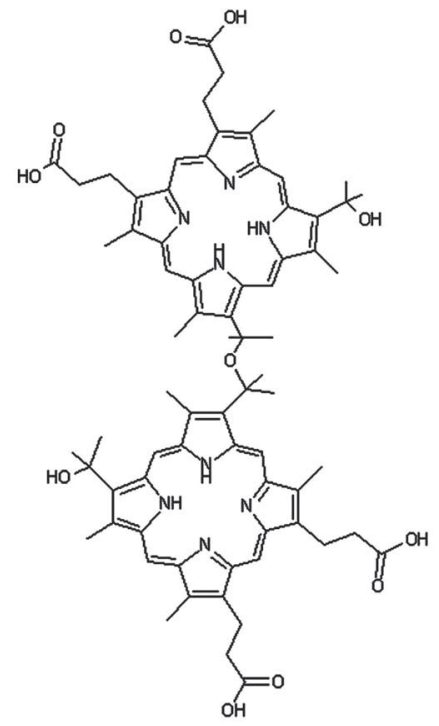

Photofrin

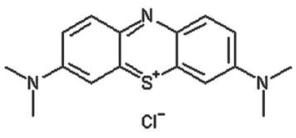

Methylene blue

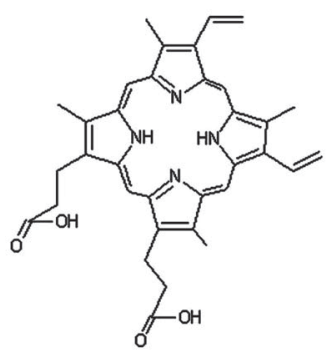

Protoporphyrin IX

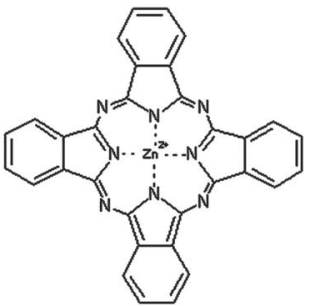

Zn (II)-phthalocyanine

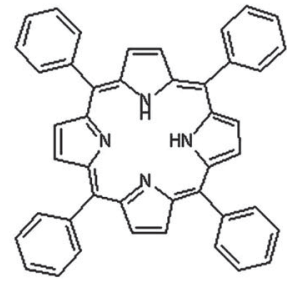

Tetraphenylporphyrin (TPP)

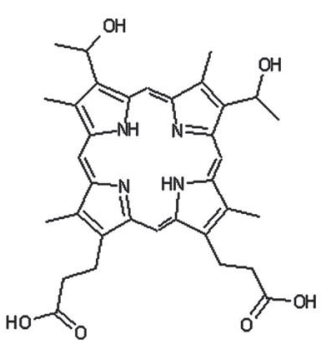

Hematoporphyrin

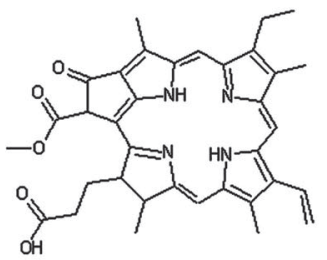

Pheophorbide a

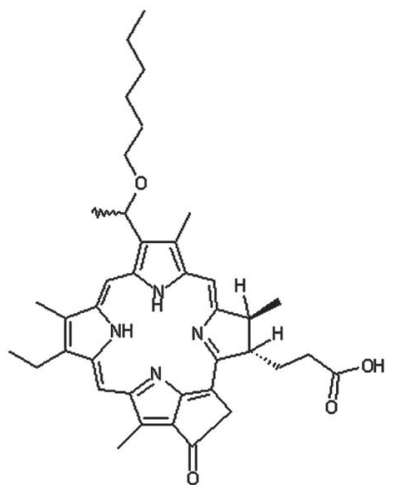

Hexylpyropheophorbide (HPPH)

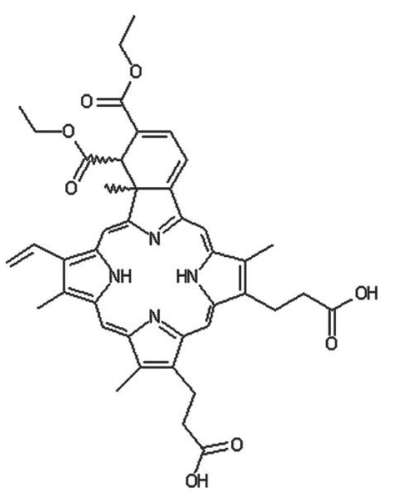

Benzoporphyrin derivative (BPD)

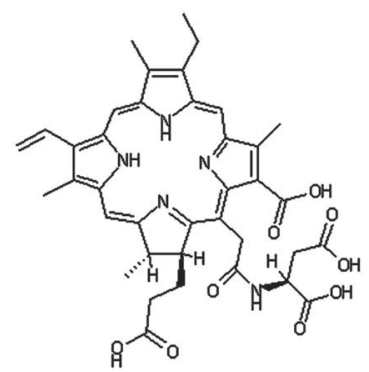

$\mathrm{N}$-chlorine e6

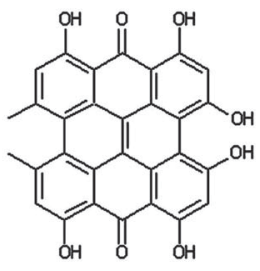

Hypericin

Figure 1. Structure of some photosensitizers used in photodynamic therapy studies. Aminolevulinic acid is not a photosensitizer but a metabolic precursor of protoporphyrin IX. 
ECM interaction and is orchestrated by cell adhesion molecules and integrin receptors, ECM components, chemoattractant molecules, matrix proteinases, and glycosidases.

In addition to the cytotoxic reaction in the target tissue (direct tumor cell killing), damage to the tumor vasculature, the immunological response associated with leukocyte stimulation, and release of inflammatory mediators like cytokines, growth factors, components of the complement system, acute phase proteins are important mechanisms for the effectiveness of PDT (3). Based on this information, in this paper we present the ECM components and their processes that have been found to be affected by PDT both in vitro and in vivo.

\section{Adhesion molecules}

Integrins, E-cadherin, selectins, intercellular adhesion molecule 1 , and vascular cell adhesion molecule 1

Integrins are class of molecules that modulates adhesion to the ECM or the endothelium, and subsequent migration through vessel walls (4) via interaction with ECM ligands, e.g., fibronectins, collagens and laminins. They are ubiquitous transmembrane adhesion molecules that form a link between the extracellular environment and the cytoskeleton. In order to function in signal transduction from one environment to the other, the integrins cluster to form focal adhesion plaques. They constitute a family of heterodimeric cell surface receptors composed of $\alpha / \beta$ subunits (5). The identity of the $\alpha / \beta$ subunits determines the ECM ligand specificity. Particular integrin/ECM interactions lead to distinct cellular responses, such as cell proliferation and differentiation. Runnels et al. (4) investigated the effects of mild (lethal dose of $15 \%$ ) benzoporphyrin-derivative monoacid ring A photosensitization on the cell adhesion properties of surviving tumor cells (ovarian carcinoma 3 ). After pho- tosensitization, $\beta_{1}$-containing integrins lost their function, as demonstrated by its diffused pattern on the cell surface, less organized into focal adhesion plaques. It is important to emphasize that this change was not due to the direct binding of the photosensitizer to the integrin receptor at the sites of ECM interaction. This is consistent with the loss of integrin ability to bind to ECM proteins, namely, collagen IV, fibronectin, laminin, and vitronectin, both in vitro and in vivo. Still, the cells retained their capacity to adhere to a collagen IV matrix, suggesting that either alternative B-subunit integrins or other adhesion molecules were used for this binding.

Another study showed that benzoporphyrin-derivative monoacid ring A PDT interfered with the ability of fibroblasts to adhere to extracellular matrices without altering integrin expression (6). Interestingly, it has been shown that photosensitization with Photofrin ${ }^{\circledR}$ caused polymorphonuclear leukocytes to adhere to the wall of normal vessel (7) but not to those of tumor capillaries (8). Despite the adherence of neutrophils to the microvascular wall after PDT in vivo, the expression of $\mathrm{P}$-selectin (one of the main adhesion molecules that bind leukocytes) by endothelial cells (EC) was not stimulated (9) but the expression of the adhesion molecule

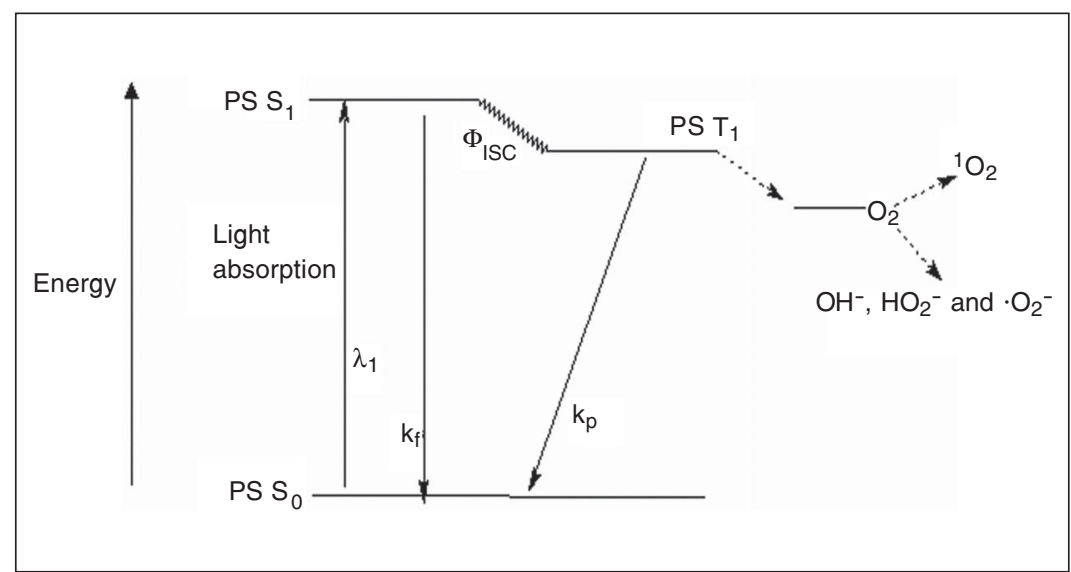

Figure 2. Photosensitization process represented by a modified Jablonski diagram. $\mathrm{PS} \mathrm{S}_{0}=$ singlet ground state photosensitizer; $P S S_{1}=$ short-lived singlet excited state photosensitizer; $P S T_{1}=$ long-lived triplet state photosensitizer; $k_{f}=$ fluorescence; $k_{p}=$ phosphorescence; $\Phi_{\text {isc }}=$ intersystem crossing; ${ }^{1} \mathrm{O}_{2}=$ singlet oxygen . 
E-selectin (expressed by inflamed endothelium) was increased in HPPH-mediated PDTtreated tumors, facilitating neutrophil migration into the tumor area (10). Intercellular adhesion molecules (ICAM) are members of the Ig superfamily expressed on the surface of EC. Integrins on the surface of leukocytes bind to this molecule in order to form more stable adhesions at sites of tissue inflammation (11). This attachment enables leukocytes to migrate through the EC of capillaries and enter the underlying tissue (Figure $3)$. The expression levels of the adhesion molecules ICAM-1 and vascular cell adhesion molecule 1 were down-regulated in EC after PDT (12). However, a marked up-regu- lation of the ICAM-1 ligands CD11b and $\mathrm{CD} 11 \mathrm{c}$, which are found on neutrophils, was also associated with PDT-treated tumors (11) (Figure 3). Following in vitro PDT, adhesiveness of malignant cells to EC, as well as their capability to invade the basement membrane (13) decline. Similarly, Vonarx et al. (14) observed that PDT using a hematoporphyrin derivative decreased the adhesiveness of colonic cancer cells to EC monolayers. The effect of PDT was also studied on cadherins, another class of adhesion molecules primarily responsible for the formation of stable junctions between cells in tissues. During cancer progression, however, E-cadherin-mediated adhesion is frequently lost (15).

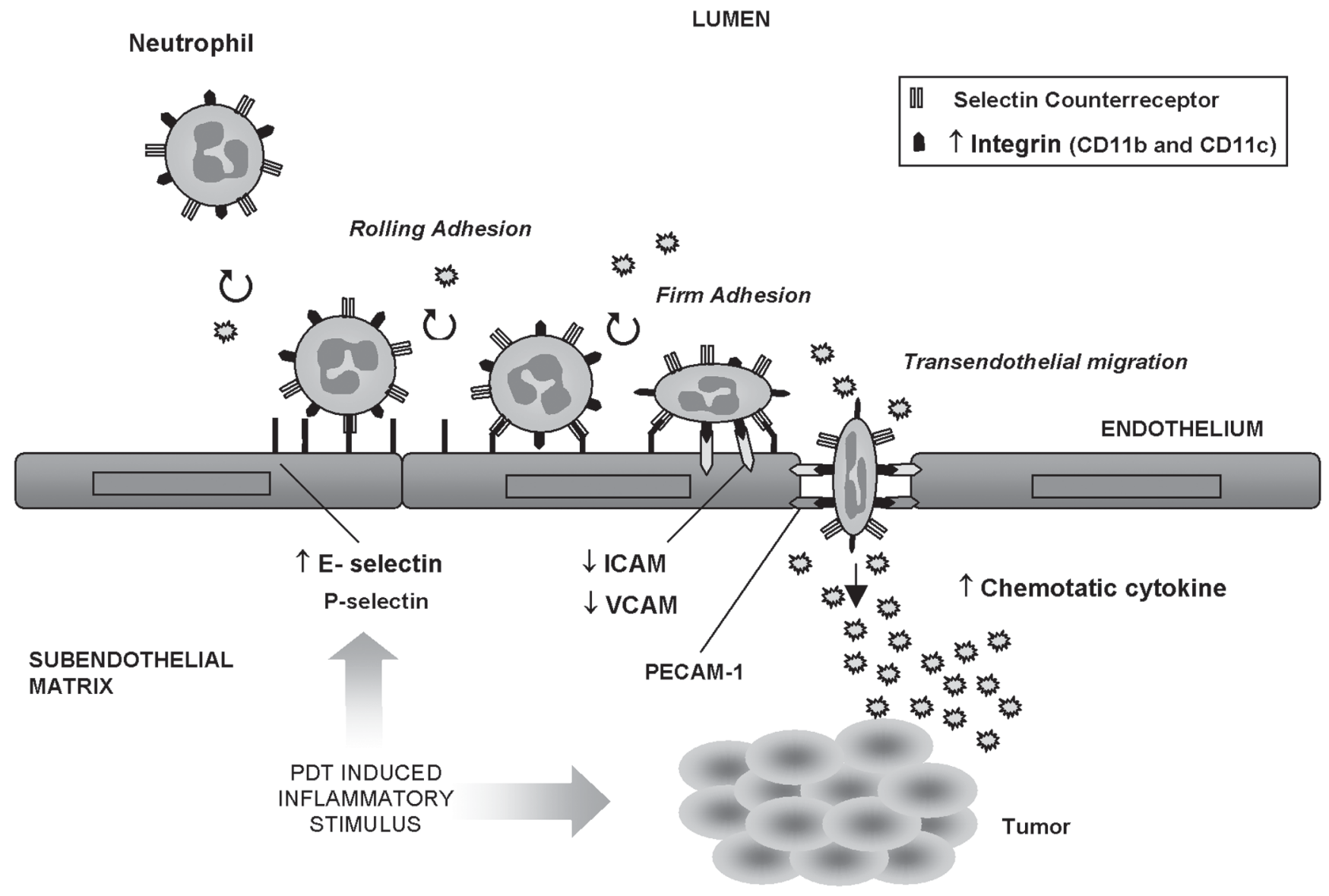

Figure 3. Photodynamic therapy (PDT)-induced inflammatory stimulus in the vascular bed: migration of neutrophils and expression of adhesion molecules. $\uparrow=$ up-regulation; $\downarrow=$ down-regulation; ICAM $=$ intercellular adhesion molecule; VCAM = vascular cell adhesion molecule; PECAM-1 $=$ platelet-endothelial cell adhesion molecule 1 . 
Human adenocarcinoma (WiDr) cells in suspension after aminolevulinic acid (ALA)PDT were unable to attach to a plastic substratum and showed redistribution of $\alpha_{\mathrm{V}} \beta_{3}$ integrin, with no change in E-cadherin expression (16). Under apoptotic conditions, zinc (II)-phthalocyanine-PDT induced a rapid disorganization of the E-cadherin-mediated cell-cell adhesion, which preceded both the detachment of cells from the substratum via $\beta_{1}$ integrins. PDT has also been reported to alter cell trypsinization in vitro. Photosensitization with pyridinium zinc (II) phthalocyanine and polyhematoporphyrin significantly decreases the efficiency of trypsinization of RIF-1 (murine fibroblasts), HT29 (human colonic carcinoma), and ECV304 (human umbilical vein endothelial cells). Also, a correlation seems to exist between increased adhesion and increased tissue transglutaminase (tTGase) activity in these cells (17). This group also proposed that the direct activation of tTGase may play a role in the increased resistance to trypsinization following pyridinium zinc (II) phthalocyaninePDT. The induction of tTGase has been linked to a suppressive effect on tumor growth (18). The same effect was obtained when sublethal ALA or disulfonated tetraphenylporphyrin-PDT inhibited trypsin-induced detachment of WiDr cells and D54Mg (glioblastoma cells) from a plastic substrate (19). Platelet adhesion to the ECM and fibrinogen can be significantly decreased after PDT of these substrates; however, PDT of collagen resulted in significantly increased platelet adhesion, with large aggregate formation (20). In addition, EC retracted after PDT, enabling neutrophils to adhere to the subendothelial matrix by their $\beta_{2}$-integrin adhesion receptors (21).

\section{Proteoglycans}

Proteoglycans are a class of glycoconjugates consisting of a core protein covalently linked to one or more linear polymers of repeating disaccharide units named glycosaminoglycans. They reside on the cell surface membrane (e.g., syndecan, decorin, glypican) or within the ECM including cartilage, basement membranes and connective tissue (e.g., versican, aggrecan, perlecan). They form a cover of negative charge, which coats virtually all animal cells, playing a role in the integrity of the ECM (22). The glycosaminoglycans found in the ECM include chondroitin/dermatan sulfates, heparan sulfates, and hyaluronan (23). Information regarding PDT and proteoglycan is scarce in the literature. In the repopulating cells of the adventitia of balloon-injured carotid arteries of rats after methylene blue-PDT there was a significant decrease in versican mRNA (24), a proteoglycan which seems to be involved in cell proliferation and is often found in tissues exhibiting elevated proliferation, as is the case during development and in a variety of tumors (25). Despite the essential role of glycosaminoglycans, research involving the effect of PDT on the metabolism of this molecule remains open.

\section{Chemical mediators}

\section{Cytokines}

Cytokines are small-secreted proteins that regulate the development and differentiation of blood cells and control the activities of lymphocytes during the immune response. If targeted cells are not destroyed, photooxidative stress leads to transcription and translation of various stress response and cytokine genes. Release of various inflammatory cytokines has been reported to be modulated by PDT (Figure 3) and factors such as tumor necrosis factor-alpha (TNF$\alpha$ ) and interleukins (IL-1ß, IL-2, IL-6, IL-8, IL-10) may also have a potential meaning for PDT effectiveness (26). Up-regulation of IL-6 was observed in Photofrin ${ }^{\circledR}$ photosensitization of epithelial HeLa (cervix carcinoma) cells (27) and EMT6 cells (mam- 
mary carcinoma) (28). In another study, hypericin photoactivation enhanced IL-6 mRNA production in poorly differentiated but not in well-differentiated nasopharyngeal cancer cells (29). Photofrin-mediated PDT of solid tumors induces host cell infiltration associated with an intense inflammatory response involving the expression of IL-1ß, TNF- $\alpha$, and IL-6 (10). Also, the decrease of the PDT-mediated tumor cure rate after blocking the functions of some cytokines proves the significance of the immunological response correlated with photosensitization (30). Diamino acid derivatives of protoporphyrin IX evoked an immunological response when the light was applied, stimulating an increase of IL-1ß and IL-6 in sera of treated mice. An interesting finding is that untreated tumor metastases localized at distant sites from the origin of the tumor, underwent regression after PDT treatment (3). This modulation shows a secondary mechanism mediated by PDT. It has been shown that PDT is able to enhance the inherent immunogenicity of at least some tumor cells, as demonstrated by its protection against subsequent tumor inoculation and induction of tumoricidal activity in the spleen and of increasing numbers of interferon (IFN)- $\gamma$-secreting splenic cells. Thus, in situ PDT amplifies the host immune response. Incubation of immature dendritic cells with PDT-generated tumor cell lysates in vitro stimulated IL-12 production, whereas incubation with UV and ionizing irradiation-generated tumor cell lysates did not. These results may indicate enhancement of PDT effectiveness in generating host antitumor immune response and potential protection against metastases outside the treatment field (31). A PDT-generated vaccine was also obtained by treating squamous cell carcinoma with a benzoporphyrin derivative and later with a lethal X-ray dose. When injected peritumorally into mice with established squamous cell carcinoma, these treated cells produced a significant therapeutic effect, including growth retardation, tumor regression and cure. Importantly, vaccine cells retrieved from the treatment site $1 \mathrm{~h}$ after injection were intermixed with dendritic cells (32). On the other hand, Jee et al. (33) reported that over-expression of IL-6 in ALAPDT-treated human basal cell carcinoma increased the anti-apoptotic activity. A number of studies have suggested that the cytokines (34) found in untreated tumors are more likely to contribute to tumor growth and progression and to immunosuppression than to promote an effective host antitumor response. For example, IL-6 is also believed to function as a growth factor for various tumors (e.g., colorectal carcinomas) (35). On the other hand, PDT-mediated reduction in function of IL-6 and other cytokine receptors prevents the occurrence of the predicted cytokine effects on cells. The altered cytokine responsiveness is predicted to affect functions of both normal and tumor cells in the post-PDT tissue environment and may determine the treatment outcome in patients undergoing PDT (36). Nevertheless, the real benefit of their up- or down-regulation for the outcome of PDT treatment of tumors remains to be investigated. Moreover, cancer incidence and progression may be subjected to functional polymorphisms of inflammatory cytokine genes and to altered expression of inflammatory cytokines (34).

\section{Growth factors and growth factor receptors}

Growth factors are polypeptides that control the growth and differentiation of animal cells. The predicted functions of growth factors and cytokines are critically dependent on the receptor status of the target cells (37). Epidermal growth factor receptor (EGFR) is over-expressed in a wide variety of solid human tumors and is considered to enhance cell proliferation, motility, adhesion, and invasion, and angiogenesis (38). As a consequence, inhibition of EGFR activity has been examined as an approach to the management 
of solid tumors (39). An inhibition of the EGF response by down-regulation of EGFR tyrosine kinase has been noted in PDT-treated cells in vitro and in vivo (40). Treatment of lung fibroblasts with ALA-PDT and Photofrin-PDT caused a marked loss $(>90 \%)$ of EGFR within the period of light treatment (36). These investigators also observed that this reduction of EGFR paralleled the loss of EGF signaling toward the ERK pathway. The same protocol applied to $\mathrm{FaDu}$ cells (squamous cell carcinoma) showed that the EGFR level decreased even further during a subsequent 1 -h culture period, besides the loss of fully processed leukemia inhibitory factor receptor $\alpha$. On the other hand, only minor reduction of oncostatin $\mathrm{M}$ receptor $\beta$ was detected in both $\mathrm{HeLa}$ and $\mathrm{FaDu}$ cells. Two other growth factors play an important role in the pathogenesis of neovascular agerelated macular degeneration. SchmidtErfurth et al. (41) observed that vascular endothelial growth factor (VEGF) and pigment epithelium-derived factor (PEDF) were up-regulated in the vascular endothelium of the choroid of treated areas, whereas they were absent in adjacent PDT-unexposed regions and in control tissue. PEDF is an antagonist of VEGF and inhibits VEGF-induced EC growth and migration, and the development of retinal neovascularization (42). PDT has a stimulating effect on the release of VEGF in murine tumors treated with Photofrin ${ }^{\circledR}$-mediated PDT (43). On the other hand, synthesis of PEDF mRNA was detected in ganglion cells, cells of the inner nuclear layer, and retinal pigment epithelial cells of normal rat eyes (44). Presumably, angiogenic inhibitors such as PEDF are responsible for the described reduction in human vascular cell migration after PDT (45), and the simultaneous release of PEDF may balance the effects of VEGF (41). Transforming growth factor (TGF) inhibits proteases involved in matrix breakdown or matrix destruction and increases the expression of a number of matrix-associated structural genes such as collagen and fibronectin (46). It was shown that chloroaluminum-sulfonated phthalocyanine-PDT inactivated the functional activity of matrix-associated growth factors such as TGF- $\beta$ and basic fibroblast growth factor (bFGF), and decreased cellular bFGF levels of PDT-treated bovine smooth muscle cells (47). In addition, it was demonstrated that PDT of collagen matrix, that mimics the cell-free vascular matrix after PDT in vivo, significantly decreased TGF- $\beta$ and bFGF mRNA levels in fibroblasts not treated with PDT (48).

\section{Prostanoids}

Prostanoids are the cyclooxygenase (COX) metabolites of arachidonic acids and exert a range of actions in the body. Treatment of tumor cells with Photofrin ${ }^{\circledR}$-based PDT releases prostanoids, including prostaglandin $\mathrm{E}_{2}\left(\mathrm{PGE}_{2}\right)$, prostacyclin and thromboxane as well as von Willebrand factor, a protein involved in platelet adhesion and aggregation $(43,49)$. Expression of the enzyme prostaglandin endoperoxide synthase 2, also known as COX-2, is regulated by nuclear factor kappa $\mathrm{B}$ and produces the inflammatory mediators known as eicosanoids (including $\mathrm{PGE}_{2}$ and leukotrienes). PDT induces increased expression of COX-2 along with increased $\mathrm{PGE}_{2}$ synthesis (50), and suppresses the expression of tissue inhibitor of metalloproteinases (51). An increase in the number of cures was obtained after systemic administration of the COX-2 inhibitor [ $N$ (2-cyclohexyloxy-4-nitrophenyl)-methane sulfonamide] (NS-398) which decreased the PDT-induced expression of both $\mathrm{PGE}_{2}$ and VEGF in BA (mouse mammary carcinoma) tumors. COX-2 inhibitors act as potentiators of the anti-tumor effectiveness of PDT when they are given after illumination. This antitumor effect is probably caused by the inhibition of angiogenesis, which is necessary for tumor regrowth (52). On the other hand, the release of thromboxane from endothelial 
cells after PDT is partly responsible for the vascular shutdown (49).

\section{Matrix metalloproteinase}

Matrix metalloproteinases (MMP) are extracellular proteolytic enzymes (endopeptidases) capable of digesting various structural components of the ECM. Growth, invasion and metastatic potential of solid tumors depend on the formation and development of new blood vessels concomitant with the degradation of the ECM. It was shown that ALA and light induced MMP-1 and MMP-3 expression in normal and scleroderma fibroblasts, besides reducing collagen type I mRNA expression (53). Also, after repeated PDT, lesional skin biopsies of patients with localized scleroderma showed a marked induction of MMP-1 in the dermis (54); a paracrine mechanism seemed to occur, as evidenced by the induction of MMP1 and MMP-3 protein levels of fibroblasts stimulated with previously PDT-treated keratinocyte medium. Thus, induction of collagen-degrading enzymes together with a reduction of collagen production was thought to be responsible for the antisclerotic effects of ALA-PDT observed in vivo (55). PDT can also increase both the expression and the enzymatic activity of MMP-9 in BA tumors (56). The inflammatory response and host cell infiltration, described previously, suggest that the increased expression of MMP-9 observed in tumor tissue after PDT involves the influx of MMP-9-expressing inflammatory host cells, as opposed to direct PDTinduced expression of MMP-9 in inflammatory cells present within tumor tissue at the time of treatment. These results demonstrate that EC and infiltrating host cells are sources of MMP-9 in PDT-treated BA tumors (56).

\section{Protein cross-linking}

As presented previously, PDT is able to induce expression of MMP. Yet, the singlet oxygen generated during PDT interacts with amino acid residues in proteins to generate reactive species. These newly generated free radicals interact with other molecules to form cross-links (57), inactivating matrix-residing growth factors. Cross-linked collagen shows an increased resistance to protease degradation. Indeed, PDT of cell-free matrix using phthalocyanine-PDT induced matrixprotein cross-linking, which resulted in resistance to metalloproteinase digestion (58). Thus, PDT might generate matrix protein cross-links, hindering invasive cellular migration (45), which was also evidenced by cell detachment from the collagen gel surface after PDT, possibly because of induced structural alterations of matrix binding sites (58). Heckenkamp et al. (48) showed that PDT had an inhibitory effect on smooth muscle cell and fibroblast migration, and no significant change in the secretion of MMP was observed. It has been theorized that $\mathrm{ECM}$ cross-linking is a major contributor to the inhibition of cell migration following PDT.

\section{Final considerations}

It is widely recognized that the interaction of cells with the ECM has profound effects on a number of biological processes, as can be observed in the intertwined relation between angiogenesis, tumorigenesis and ECM metabolism. For this reason, postPDT responses involving ECM components help to modulate the fate of cells, especially the surviving cells. This occurs because the effects of PDT are not limited to the site where photosensitization takes place, but is rather propagated in a chain reaction. For example, PDT can induce a complex immune response that may enhance anti-tumor immunity. ECM components will be affected, even when they are not the primary targets, and thus modulation of this interaction as a result of photosensitization is of great importance. As Castano and colleagues (59) 
stated in a recent review, the ideal cancer therapy, besides destroying the primary tumor, should also trigger the immune system to recognize, pursue and destroy any remaining tumor cells, located either at or near the site of the primary tumor, or distant micrometastases. We should also keep in mind that the action of PDT on specific molecular pathways depends on cell line, fluence rate and photosensitizer used. Table 1 summarizes the information discussed in the preceding sections regarding the investigation of various aspects of PDT modulation of the ECM and related components. Other important molecules involved in the regulation of cellular functions, such as proteoglycans, deserve more attention for a better understanding of the effects of photosensitization on the remaining surviving cells and on the tissue bed as a whole. Finally, besides the dual selectivity of PDT, that is the photosensitizer localization in the target tissue and

Table 1. Summary of the effect of photodynamic therapy (PDT) on some molecules of the extracellular matrix and related components.

\begin{tabular}{|c|c|c|}
\hline Molecules & Modifications induced by PDT & $\begin{array}{l}\text { Related } \\
\text { references }\end{array}$ \\
\hline \multicolumn{3}{|l|}{ Adhesion molecules } \\
\hline E-selectin & $\uparrow$ & 10 \\
\hline ICAM-1; VCAM-1 & $\downarrow$ & 12 \\
\hline CD11b; CD11c & $\uparrow$ & 11 \\
\hline tTGase & $\uparrow$ & 17,19 \\
\hline$B_{1}$-containing integrins & Loss of functionality & 4 \\
\hline E-cadherin & $\begin{array}{l}\text { Disorganization of E-cadherin } \\
\text { mediated cell-cell adhesion }\end{array}$ & 16 \\
\hline \multicolumn{3}{|l|}{ Proteoglycans } \\
\hline Versican mRNA & $\downarrow$ & 24 \\
\hline \multicolumn{3}{|l|}{ Collagens } \\
\hline Collagen-1 & $\downarrow$ & 53 \\
\hline \multicolumn{3}{|l|}{ Growth factors and growth factor receptors } \\
\hline Epidermal growth factor receptor & $\downarrow$ or loss & 36,40 \\
\hline Oncostatin $\mathrm{M}$ receptor $B$ & $\downarrow$ & 36 \\
\hline Vascular endothelial growth factor & $\uparrow$ & 41,43 \\
\hline Pigment epithelium-derived factor & $\uparrow$ & 41 \\
\hline $\begin{array}{l}\text { Basic fibroblast growth factor; } \\
\text { transformin growth factor- } \beta\end{array}$ & $\downarrow$ or inactivation & 47,48 \\
\hline Leukemia inhibitory factor receptor $\alpha$ & loss & 36 \\
\hline \multicolumn{3}{|l|}{ Cytokines } \\
\hline Interleukin-6 & $\uparrow$ & $10,27,28,29,33$ \\
\hline Tumor necrosis factor- $\alpha$; interleukin- $1 \beta$ & $\uparrow$ & 10 \\
\hline Interferon- $\gamma$ & $\uparrow$ & 31 \\
\hline Interleukin-12 & $\uparrow$ & 31 \\
\hline Interleukin-6 receptor and other cytokine receptors & $\downarrow$ & 36 \\
\hline \multicolumn{3}{|l|}{ Prostanoids } \\
\hline Prostaglandin $\mathrm{E}_{2}$ & $\uparrow$ & $43,49,50$ \\
\hline Thromboxane; von Willebrand factor & $\uparrow$ & 43,49 \\
\hline \multicolumn{3}{|l|}{ Matrix metalloproteinases (MMP) } \\
\hline MMP-1 & $\uparrow$ & 53,54 \\
\hline MMP-3 & $\uparrow$ & 53 \\
\hline MMP-9 & $\uparrow$ & 56 \\
\hline Tissue inhibitor of metalloproteinase 1 & $\downarrow$ & 51 \\
\hline
\end{tabular}

ICAM-1 = intercellular adhesion molecule 1; VCAM-1 = vascular cell adhesion molecule 1 ; tTGase = tissue transglutaminase; $\uparrow=$ up-regulation; $\downarrow=$ down-regulation. 
the light spatially focused on the lesion, the secondary effects related to the modulation of ECM components and molecules of the immune system emerge as complementary PDT feature that may be useful to enhance the treatment outcome.

\section{References}

1. Dougherty TJ. An update on photodynamic therapy applications. $J$ Clin Laser Med Surg 2002; 20: 3-7.

2. Hay ED. Cell biology of the extracellular matrix. 2nd edn. New York: Plenum Press; 1991.

3. van Duijnhoven FH, Aalbers RI, Rovers JP, Terpstra OT, Kuppen PJ. The immunological consequences of photodynamic treatment of cancer, a literature review. Immunobiology 2003; 207: 105-113.

4. Runnels JM, Chen N, Ortel B, Kato D, Hasan T. BPD-MA-mediated photosensitization in vitro and in vivo: cellular adhesion and beta1 integrin expression in ovarian cancer cells. Br J Cancer 1999; 80: 946-953.

5. Yamada KM, Pankov R, Cukierman E. Dimensions and dynamics in integrin function. Braz J Med Biol Res 2003; 36: 959-966.

6. Margaron P, Sorrenti R, Levy JG. Photodynamic therapy inhibits cell adhesion without altering integrin expression. Biochim Biophys Acta 1997; 1359: 200-210.

7. Fingar VH, Wieman TJ, Wiehle SA, Cerrito PB. The role of microvascular damage in photodynamic therapy: the effect of treatment on vessel constriction, permeability, and leukocyte adhesion. Cancer Res 1992; 52: 4914-4921.

8. Dellian M, Abels C, Kuhnle GE, Goetz AE. Effects of photodynamic therapy on leucocyte-endothelium interaction: differences between normal and tumour tissue. Br J Cancer 1995; 72: 1125-1130.

9. Sluiter W, de Vree WJ, Pietersma A, Koster JF. Prevention of late lumen loss after coronary angioplasty by photodynamic therapy: role of activated neutrophils. Mol Cell Biochem 1996; 157: 233-238.

10. Gollnick SO, Evans SS, Baumann H, Owczarczak B, Maier P, Vaughan L, et al. Role of cytokines in photodynamic therapy-induced local and systemic inflammation. Br J Cancer 2003; 88: 17721779.

11. Castano AP, Demidova TN, Hamblin MR. Mechanisms in photodynamic therapy: part two-cellular signaling, cell metabolism and modes of cell death. Photodiagn Photodyn Ther 2005; 2: 1-23.

12. Volanti C, Gloire G, Vanderplasschen A, Jacobs N, Habraken $Y$, Piette J. Downregulation of ICAM-1 and VCAM-1 expression in endothelial cells treated by photodynamic therapy. Oncogene 2004; 23: 8649-8658.

13. Jiang F, Chopp M, Katakowski M, Cho KK, Yang X, Hochbaum N, et al. Photodynamic therapy with photofrin reduces invasiveness of malignant human glioma cells. Lasers Med Sci 2002; 17: 280-288.

14. Vonarx V, Foultier MT, Xavier de BL, Anasagasti L, Morlet L, Patrice $\mathrm{T}$. Photodynamic therapy decreases cancer colonic cell adhesiveness and metastatic potential. Res Exp Med 1995; 195: 101-116.

15. Cavallaro U, Christofori G. Multitasking in tumor progression: signaling functions of cell adhesion molecules. Ann N Y Acad Sci 2004; 1014: $58-66$

16. Uzdensky AB, Juzeniene A, Kolpakova E, Hjortland GO, Juzenas P, Moan J. Photosensitization with protoporphyrin IX inhibits attachment of cancer cells to a substratum. Biochem Biophys Res Commun 2004; 322: 452-457.

17. Ball DJ, Mayhew S, Vernon DI, Griffin M, Brown SB. Decreased efficiency of trypsinization of cells following photodynamic therapy: evaluation of a role for tissue transglutaminase. Photochem
Photobiol 2001; 73: 47-53.

18. Johnson TS, Knight CR, el-Alaoui S, Mian S, Rees RC, Gentile V, et al. Transfection of tissue transglutaminase into a highly malignant hamster fibrosarcoma leads to a reduced incidence of primary tumour growth. Oncogene 1994; 9: 2935-2942.

19. Uzdensky A, Juzeniene A, Ma LW, Moan J. Photodynamic inhibition of enzymatic detachment of human cancer cells from a substratum. Biochim Biophys Acta 2004; 1670: 1-11.

20. Fungaloi $P$, Statius van Eps R, Wu YP, Blankensteijn J, de Groot P, van Uurk $\mathrm{H}$, et al. Platelet adhesion to photodynamic therapy-treated extracellular matrix proteins. Photochem Photobiol 2002; 75: 412417.

21. de Vree WJ, Fontijne-Dorsman AN, Koster JF, Sluiter W. Photodynamic treatment of human endothelial cells promotes the adherence of neutrophils in vitro. Br J Cancer 1996; 73: 1335-1340.

22. Lopes CC, Dietrich CP, Nader HB. Specific structural features of syndecans and heparan sulfate chains are needed for cell signaling. Braz J Med Biol Res 2006; 39: 157-167.

23. Taylor KR, Gallo RL. Glycosaminoglycans and their proteoglycans: host-associated molecular patterns for initiation and modulation of inflammation. FASEB J 2006; 20: 9-22.

24. Heckenkamp J, Adili F, Kishimoto J, Koch M, Lamuraglia GM. Local photodynamic action of methylene blue favorably modulates the postinterventional vascular wound healing response. J Vasc Surg 2000; 31: 1168-1177.

25. Wight TN. Versican: a versatile extracellular matrix proteoglycan in cell biology. Curr Opin Cell Biol 2002; 14: 617-623.

26. Yom SS, Busch TM, Friedberg JS, Wileyto EP, Smith D, Glatstein E, et al. Elevated serum cytokine levels in mesothelioma patients who have undergone pleurectomy or extrapleural pneumonectomy and adjuvant intraoperative photodynamic therapy. Photochem Photobiol 2003; 78: 75-81.

27. Kick G, Messer G, Plewig G, Kind P, Goetz AE. Strong and prolonged induction of $\mathrm{C}$-jun and $\mathrm{c}$-fos proto-oncogenes by photodynamic therapy. Br J Cancer 1996; 74: 30-36.

28. Gollnick SO, Liu X, Owczarczak B, Musser DA, Henderson BW. Altered expression of interleukin 6 and interleukin 10 as a result of photodynamic therapy in vivo. Cancer Res 1997; 57: 3904-3909.

29. Du H, Bay BH, Mahendran R, Olivo M. Hypericin-mediated photodynamic therapy elicits differential interleukin- 6 response in nasopharyngeal cancer. Cancer Lett 2006; 235: 202-208.

30. Dougherty TJ, Gomer CJ, Henderson BW, Jori G, Kessel D, Korbelik M, et al. Photodynamic therapy. J Natl Cancer Inst 1998; 90: 889905.

31. Gollnick SO, Vaughan L, Henderson BW. Generation of effective antitumor vaccines using photodynamic therapy. Cancer Res 2002; 62: 1604-1608.

32. Korbelik M, Sun J. Photodynamic therapy-generated vaccine for cancer therapy. Cancer Immunol Immunother 2006; 55: 900-909.

33. Jee SH, Shen SC, Chiu HC, Tsai WL, Kuo ML. Overexpression of interleukin-6 in human basal cell carcinoma cell lines increases antiapoptotic activity and tumorigenic potency. Oncogene 2001; 20: 198-208. 
34. Balkwill F, Mantovani A. Inflammation and cancer: back to Virchow? Lancet 2001; 357: 539-545.

35. Kinoshita $T$, Ito $H$, Miki $C$. Serum interleukin-6 level reflects the tumor proliferative activity in patients with colorectal carcinoma. Cancer 1999; 85: 2526-2531.

36. Wong TW, Tracy E, Oseroff AR, Baumann H. Photodynamic therapy mediates immediate loss of cellular responsiveness to cytokines and growth factors. Cancer Res 2003; 63: 3812-3818.

37. Agostinis P, Assefa Z, Vantieghem A, Vandenheede JR, Merlevede W, De Witte P. Apoptotic and anti-apoptotic signaling pathways induced by photodynamic therapy with hypericin. Adv Enzyme Regul 2000; 40: 157-182.

38. Spaulding DC, Spaulding BO. Epidermal growth factor receptor expression and measurement in solid tumors. Semin Oncol 2002; 29: 45-54.

39. Fry DW. Inhibition of the epidermal growth factor receptor family of tyrosine kinases as an approach to cancer chemotherapy: progression from reversible to irreversible inhibitors. Pharmacol Ther 1999; 82: $207-218$

40. Ahmad N, Kalka K, Mukhtar $\mathrm{H}$. In vitro and in vivo inhibition of epidermal growth factor receptor-tyrosine kinase pathway by photodynamic therapy. Oncogene 2001; 20: 2314-2317.

41. Schmidt-Erfurth U, Schlotzer-Schrehard U, Cursiefen C, Michels S, Beckendorf A, Naumann GO. Influence of photodynamic therapy on expression of vascular endothelial growth factor (VEGF), VEGF receptor 3, and pigment epithelium-derived factor. Invest Ophthalmol Vis Sci 2003; 44: 4473-4480.

42. Duh EJ, Yang HS, Suzuma I, Miyagi M, Youngman E, Mori K, et al. Pigment epithelium-derived factor suppresses ischemia-induced retinal neovascularization and VEGF-induced migration and growth. Invest Ophthalmol Vis Sci 2002; 43: 821-829.

43. Ferrario A, von Tiehl KF, Rucker N, Schwarz MA, Gill PS, Gomer CJ. Antiangiogenic treatment enhances photodynamic therapy responsiveness in a mouse mammary carcinoma. Cancer Res 2000; 60: 4066-4069.

44. Ogata N, Wada M, Otsuji T, Jo N, Tombran-Tink J, Matsumura M. Expression of pigment epithelium-derived factor in normal adult rat eye and experimental choroidal neovascularization. Invest Ophthalmol Vis Sci 2002; 43: 1168-1175.

45. Waterman PR, Overhaus M, Heckenkamp J, Nigri GR, Fungaloi PF, Landis ME, et al. Mechanisms of reduced human vascular cell migration after photodynamic therapy. Photochem Photobiol 2002; 75: 46-50.

46. Bonewald LF. Regulation and regulatory activities of transforming growth factor beta. Crit Rev Eukaryot Gene Expr 1999; 9: 33-44.

47. Statius van Eps RG, Adili F, Watkins MT, Anderson RR, Lamuraglia GM. Photodynamic therapy of extracellular matrix stimulates endo- thelial cell growth by inactivation of matrix-associated transforming growth factor-beta. Lab Invest 1997; 76: 257-266.

48. Heckenkamp J, Aleksic M, Gawenda M, Breuer S, Brabender J, Mahdavi A, et al. Modulation of human adventitial fibroblast function by photodynamic therapy of collagen matrix. Eur J Vasc Endovasc Surg 2004; 28: 651-659.

49. Fingar VH, Wieman TJ, Doak KW. Role of thromboxane and prostacyclin release on photodynamic therapy-induced tumor destruction. Cancer Res 1990; 50: 2599-2603.

50. Hendrickx N, Volanti C, Moens U, Seternes OM, De Witte P, Vandenheede JR, et al. Up-regulation of cyclooxygenase-2 and apoptosis resistance by $\mathrm{p} 38$ MAPK in hypericin-mediated photodynamic therapy of human cancer cells. J Biol Chem 2003; 278: 52231-52239.

51. Ferrario A, von Tiehl K, Wong S, Luna M, Gomer CJ. Cyclooxygenase-2 inhibitor treatment enhances photodynamic therapy-mediated tumor response. Cancer Res 2002; 62: 3956-3961.

52. Makowski M, Grzela T, Niderla J, Lazarczyk M, Mroz P, Kopee M, et al. Inhibition of cyclooxygenase-2 indirectly potentiates antitumor effects of photodynamic therapy in mice. Clin Cancer Res 2003; 9: 5417-5422.

53. Karrer S, Bosserhoff AK, Weiderer P, Landthaler M, Szeimies RM Influence of 5-aminolevulinic acid and red light on collagen metabolism of human dermal fibroblasts. J Invest Dermatol 2003; 120: 325331.

54. Karrer S, Abels C, Weiderer P, Bosserhoff A, Landthaler M, Szeimies $\mathrm{RM}$. Induction of collagenases in human dermal fibroblasts by 5 aminolevulinic acid and light. Med Laser Appl 2001; 16: 148 (Abstract).

55. Karrer S, Bosserhoff AK, Weiderer P, Landthaler M, Szeimies RM. Keratinocyte-derived cytokines after photodynamic therapy and their paracrine induction of matrix metalloproteinases in fibroblasts. $\mathrm{Br} \mathrm{J}$ Dermatol 2004; 151: 776-783.

56. Ferrario A, Chantrain CF, von Tiehl K, Buckley S, Rucker N, Shalinsky DR, et al. The matrix metalloproteinase inhibitor prinomastat enhances photodynamic therapy responsiveness in a mouse tumor model. Cancer Res 2004; 64: 2328-2332.

57. Shen HR, Spikes JD, Kopecekova P, Kopecek J. Photodynamic crosslinking of proteins. I. Model studies using histidine- and lysinecontaining N-(2-hydroxypropyl)methacrylamide copolymers. J Photochem Photobiol B 1996; 34: 203-210.

58. Overhaus M, Heckenkamp J, Kossodo S, Leszczynski D, Lamuraglia GM. Photodynamic therapy generates a matrix barrier to invasive vascular cell migration. Circ Res 2000; 86: 334-340.

59. Castano AP, Mroz P, Hamblin MR. Photodynamic therapy and antitumour immunity. Nat Rev Cancer 2006; 6: 535-545. 